This item was submitted to Loughborough's Research Repository by the author.

Items in Figshare are protected by copyright, with all rights reserved, unless otherwise indicated.

\title{
A unified ecological framework for studying effects of digital places on well- being
}

PLEASE CITE THE PUBLISHED VERSION

https://doi.org/10.1016/j.socscimed.2018.09.022

PUBLISHER

(C) Elsevier

VERSION

AM (Accepted Manuscript)

\section{PUBLISHER STATEMENT}

This paper was accepted for publication in the journal Social Science and Medicine and the definitive published version is available at https://doi.org/10.1016/j.socscimed.2018.09.022.

\section{LICENCE}

CC BY-NC-ND 4.0

\section{REPOSITORY RECORD}

Shankardass, Ketan, Colin Robertson, Krystelle Shaughnessy, Martin Sykora, and Rob Feick. 2018. "A Unified Ecological Framework for Studying Effects of Digital Places on Well-being”. Loughborough University. https://hdl.handle.net/2134/35689. 
A Unified Ecological Framework for Studying Effects of Digital Places on Well-being Ketan Shankardass ${ }^{1 *}$, Colin Robertson ${ }^{2}$, Krystelle Shaughnessy ${ }^{3}$, Martin Sykora ${ }^{4}$ and Rob Feick ${ }^{5}$

${ }^{1}$ Department of Health Sciences, Wilfrid Laurier University, 75 University Ave W, Waterloo, Ontario, Canada, N2L 3C5; kshankardass@wlu.ca; Telephone: +1.519.884.0710 x4316

${ }^{4}$ Department of Geography and Environmental Studies, Wilfrid Laurier University, 75 University Ave W, Waterloo, Ontario, Canada, N2L 3C5; crobertson@wlu.ca

${ }^{5}$ Department of Psychology, Faculty of Social Sciences, 136 Jean-Jacques Lussier, Vanier Hall, Ottawa, Ontario, Canada, K1N 6N5; Krystelle.Shaughnessy@uottawa.ca

${ }^{6}$ Centre for Information Management, School of Business and Economics, Loughborough University, Epinal Way, Loughborough, Leicestershire, UK, LE11 3TU; M.D.Sykora@lboro.ac.uk

${ }^{7}$ School of Planning, University of Waterloo, Ring Rd, Waterloo, Ontario, Canada, N2L 3G1; robert.feick@uwaterloo.ca

* indicates corresponding author 
Acknowledgements
Acknowledgements

We are grateful for this work to be supported by an SSHRC (Social Sciences and Humanities Research

Council) Partnership Development grant and partly by an internal grant from Wilfrid Laurier University.

\section{Acknowledgements}

Council) Parthership Development grant and partly by an internal grant from Wifrid Laurier University. 


\section{A Unified Ecological Framework for Studying Effects of Digital Places on Well-being}

\section{Highlights}

Social media has expanded opportunities to study place and well-being.

The discourse on place effects on well-being largely excludes digital places.

Interactions in digital places includes surrounding physical environments.

We present a unified ecological framework of place effects on well-being. 


\section{Abstract}

Social media has greatly expanded opportunities to study place and well-being through the availability of human expressions tagged with physical location. Such research often uses social media content to study how specific places in the offline world influence well-being without acknowledging that digital platforms (e.g., Twitter, Facebook, Youtube, Yelp) are designed in unique ways that structure certain types of interactions in online and offline worlds, which can influence place-making and well-being. To expand our understanding of the mechanisms that influence social media expressions about well-being, we describe an ecological framework of person-place interactions that asks, "at what broad levels of interaction with digital platforms and physical environments do effects on well-being manifest?" The person is at the centre of the ecological framework to recognize how people define and organize both digital and physical communities and interactions. The relevance of interactions in physical environments depends on the built and natural characteristics encountered across modes of activity (e.g., domestic, work, study). Here, social interactions are stratified into the meso-social (e.g., local social norms) and micro-social (e.g., personal conversations) levels. The relevance of interactions in digital platforms is contingent on specific hardware and software elements. Social interactions at the meso-social level include platform norms and passive use of social media, such as observing the expressions of others, whereas interactions at the micro-level include more active uses, like direct messaging. Digital platforms are accessed in a physical location, and physical locations are partly experienced through online interactions; therefore, interactions between these environments are also acknowledged. We conclude by discussing the strengths and limitations of applying the framework to studies of place and well-being.

Keywords: Place; well-being; social media; conceptual framework, social interaction 
A Unified Ecological Framework for Studying Effects of Digital Places on Well-being

\section{Manuscript}

"As bandwidth burgeons and computing muscle continues to grow, cyberspace places will present themselves in increasingly multisensory and engaging ways. They will look, sound, and feel more realistic, they will enable richer self-representations of their users, they will respond to user actions in real time and in complex ways, and they will be increasingly elaborate and artfully designed. We will not just look at them; we will feel present in them. We can expect them to evolve into the elements of cyberspace construction - constituents of a new architecture without tectonics and a new urbanism freed from the constraints of physical space." (pp.114-115, Mitchell, 1996)

\section{Introduction}

\subsection{Summary}

The growing penetration of digital and online networks (e.g., social media sites/apps, bulletin boards, virtual worlds and video games, websites) into our personal, social, and physical lives draws increasing attention to the myriad ways these technologies influence well-being (e.g., Fergie, Hunt and Hilton, 2016). As these digital platforms have become more mobile and deployed to a wider set of connected objects with which we interact, the distinction between the online and offline worlds has become less clear (e.g., finding your way through places using Google Maps, discovering a satisfying place to eat on Yelp, or pursuing Pokémon Go characters around a city). The concept of place in geography has been simply described as physical environments (spaces) with meaning and utility (Moon, 1990), which reflects how humans subjectively (e.g., my home, my place of work) and objectively (e.g., the City of Toronto) give rise to places. Digital platforms have also been described as places where meaning arises through interactions with digital platforms and surrounding physical environments (i.e., a fusion of experiences in digital and physical places) (Horan, 2001). Our understanding of how our use of digital places over time influences our well-being is in its 


\section{A Unified Ecological Framework for Studying Effects of Digital Places on Well-being}

infancy. Traditional tools and frameworks for understanding place effects on well-being fail to capture the reality of lived experience using digital platforms.

Interactions within places and the linkages between our interactions with digital platforms and surrounding physical environments can help to explain place effects on well-being. In relation to digital places, these interactions and linkages are uncertain, often person-specific, and may require reconsideration of concepts (e.g., community, geographic scale) already wellestablished in the substantial discourse about how physical places influence well-being (e.g., Cummins et al, 2007; Keen et al, 2010; Lengen \& Kistemann, 2012; Macintyre et al, 2002; Mitchell et al, 2013; Squires \& Kubrin, 2005). In this paper, we present an ecological framework that articulates multiple levels of these interactions that may influence a person's well-being. Prior to introducing this framework, definitions important in this problem space and a rationale for the research are presented using a selection of existing theory and evidence. We conclude by discussing some strengths and limitations of this framework, and potential applications and related challenges.

\subsection{Basic definitions and concepts}

Places are human-mediated representations of physical spaces bounded by built and natural characteristics, including a wide array of personal socio-spatial regions (e.g., my home, the jail, my city, their country) and specific locations (e.g., 5225 Figueroa Mountain Road; Echo Park, Los Angeles; City of Dundas; 49 $\left.24^{\prime} 55^{\prime \prime} \mathrm{N},-123^{\circ} 07^{\prime} 17^{\prime \prime} \mathrm{N}\right)$. Places are sometimes described in terms of their social construction and how they are experienced socially (see Kearns and Moon, 2002). All of this has to be considered over time since physical and social environments can be quite dynamic (McHugh \& Mings, 1996). Some have used "landscapes" as "a metaphor for the complex layerings of history, social structure and built environment that converge in particular places" (Ibid., p. 611), such as therapeutic landscapes (Gesler, 1992), and 
A Unified Ecological Framework for Studying Effects of Digital Places on Well-being

landscapes of despair (Dear \& Wolch, 1987). Thus, places are abstract ideas constructed by people to create meaningful separations of space over time.

Digital platforms in their current form (e.g., Twitter, Facebook, Yelp, Google Maps, Runescape 3) can be seen as part of an evolving assemblage of digital objects which has become an increasingly ubiquitous locus of human interaction over the last two decades. Horan (2001) described digital places as experienced with both "physical and electronic characteristics" imbued with "digital technologies and infrastructures" that evolve over time (i.e., they are modifiable). Like geographical places, digital places are also are defined socially: designed to be experienced in some socially constructed manner, and are rooted in a sociopolitical context. And yet, the experience of using various digital platforms always involves some physical infrastructure at the device and network levels, and other physical experiences related to the built and natural characteristics of the surrounding physical environment (Malecki 2017). For many people, use of digital places has become pervasive as information and communications technologies (ICTs) imbue activity during work, home, and recreation periods and are increasingly enabled through location-aware mobile devices. This shift to being "always connected" across multiple times and locations manifests itself through a series of digital places that represent virtual counterparts to their concurrent physical geographies. This raises questions about how using digital places, and even having them replace physical places for some common uses (e.g., earning a degree, being social, playing sports), influences well-being.

Well-being can be defined as a broad concept that encompasses physical, emotional, mental, social and spiritual dimensions (Eberst, 1994; Huppert \& So, 2013). This includes biomedical understandings of health outcomes (i.e., the presence and absence of disease pathology and endpoints), as well as encompassing a range of other short- and long-term processes and behaviours that indicate wellness, such as positive affective states (e.g., happiness), health behaviours (e.g., physical activity), life satisfaction and meaning, 


\section{A Unified Ecological Framework for Studying Effects of Digital Places on Well-being}

development and competence, vitality, self-esteem, social engagement and positive relationships, and resilience.

Our goal for this framework is to facilitate research about how and why our interactions with digital platforms in physical environments impact on processes, behaviour, and outcomes pertaining to all aspects of well-being; that is, to help better understand digital place effects on well-being. In doing so, we acknowledge that there is a bidirectional relationship at work; that the well-being of individuals and composition of wellness across a population can shape places. For example, in physical places with a high proportion of elderly residents there will be more mobility issues to accommodate by composition, and also a greater burden of chronic disease than in places with a younger demographic composition. This may lead governments, local businesses and community organizations to improve the accessibility of local built and natural characteristics (e.g., shops, parks), and provide sufficient medical services and supplies locally. Similarly, an app designed to allow elderly residents to find local health services information might also contain advertising that negatively impacts or exploits its users. As well, these impacts will vary geographically, with complex patterns arising from residential, social, and activity patterns.

Studies about digital place effects on well-being are recent and have been largely focused on social media platforms, which are ripe with data given that they have attracted billions of individual users globally to share their thoughts and feelings to public and private audiences through various forms of expression (e.g., posts, tweets, comments). Social media generally refers to Internet-based applications and user-created content that are built on the ideas and technologies of Web 2.0 with user-specific profiles, and connections between individual users or groups (e.g., Obar \& Wildman, 2015). Although social media platforms, such as Facebook and Twitter, were still in their infancy when Horan conceptualized digital places, they have since achieved a much greater presence in the world. 
A Unified Ecological Framework for Studying Effects of Digital Places on Well-being

\subsection{Rationale}

\subsubsection{Physical and digital place effects on well-being}

A large, vibrant literature continues to expand our understanding of the complex relationship between physical places and well-being while highlighting the relevance of interactions with physical (i.e., built, natural), social and macro-social characteristics of physical places for understanding effects on well-being. Within this discourse, some researchers have focused on understanding how places influence well-being generally (i.e., not in relation to a specific aspect of well-being). For example, Bernard et al (2007) propose a detailed framework of neighbourhood places that explains how four rules (i.e., right, price, informal reciprocity, proximity) determine the accessibility of local resources related to five domains of the physical and social environment (i.e., physical, economic, community organizations, local sociability, institutional). Macintyre et al (2002) use evidence and experience from the West of Scotland to propose five overlapping features of neighbourhoods that influence well-being (e.g., sociocultural features, such as incivilities and other threats to personal safety); while later, Cummins et al (2007) describe a "mutually reinforcing and reciprocal relationship" (p. 1835) between people and places that helps to explain these influences. Well-being may be impacted by one's "sense of place", which includes one's beliefs about the relationships between themselves and a place (place identity), their feelings about the place (place attachment), and the behavioral exclusivity of the place in relation to alternatives (place dependence) (Jorgensen \& Stedman, 2001). A body of evidence also describes neurobiological mechanisms (e.g., perception to recognition and representation) that imply an interaction between place and the brain (Lengen \& Kistemann, 2012).

Other researchers have illuminated ways that interactions with physical places influence specific aspects of well-being. For example, some literature explores how the presence of stressful environmental characteristics and the accessibility of resources in neighbourhoods 
A Unified Ecological Framework for Studying Effects of Digital Places on Well-being

affect psychological well-being by influencing the experience of stress and coping responses (Shankardass, 2012; Dupéré \& Perkins, 2007). Another body of evidence describes how transport, land-use and social service planning can create and reinforce social exclusion and poverty (i.e., social and economic well-being), in part through effects on neighbourhood reputation and residents' self-esteem (see: Macintyre et al, 2002; Cummins et al, 2007). Luginaah et al (2002) describe how changes in appraisal of odor perception and annoyance of residents living near a petroleum refinery influenced illness reporting. Keen et al (2010) and Squires \& Kubrin (2005) explore how social stigma and development processes leave some racialized communities with fewer opportunities for personal development.

The examination of how interactions in digital places impact well-being is an emerging field. Research findings have begun to highlight how interactions with ICTs, including social media, are correlated with positive (e.g. gains in social capital, reduced depression) and negative (e.g. physical isolation, social comparison, envy) aspects of physical, mental, and spiritual well-being (Choi and DiNitto, 2013; Pearce and Rice, 2013; Appel, Gerlach \& Crusius, 2016; Shakya \& Christakis, 2017). Some studies raise interesting ideas about the specific mechanisms at work; for example, more passive, observational use of social media can be both harmful (e.g., due to social comparisons leading to feelings of envy) and healthy (e.g., by facilitating knowledge gathering). However, there has been less theory developed to date about how interactions with specific digital places influence well-being in the context of interactions with physical places.

In expanding our understanding of how digital places influence well-being, we might also look to sociological approaches, which have elaborated on how place effects in physical settings operate in part through their design (think: built characteristics), which can encourage or discourage social interaction, and thereby increase or decrease potential social influence (Logan, 2012). This is highly relevant since most digital platforms are explicitly designed as 


\section{A Unified Ecological Framework for Studying Effects of Digital Places on Well-being}

social networks (i.e., to encourage social interactions); although platforms such as Facebook and Twitter have unique approaches to encouraging and limiting social interaction, such as the unique modes available for responding to posts and restrictions on sending private messages to other users. According to sociologists, the design of places can influence well-being in a variety of ways, including by embodying and entrenching otherwise intangible cultural norms, identities and memories that facilitate social structural patterns (e.g., categories, differences and hierarchies); and by arranging chance face-to-face interactions (e.g., through the design of staircases at places of work), thus shaping the formation of social networks and, potentially, stronger or weaker communities (Gieryn, 2000).

\subsubsection{The rise of geosocial media}

A comparatively small, but rapidly increasing proportion of social media is now encoded with geographic coordinates ("geosocial data") that are captured without user intervention by their mobile devices' cellular network connections and/or GPS-defined locations (Croitoru, Crooks, Radzikowski and Stefanidis, 2013). Geosocial data encompasses a variety of media forms (e.g. photographs shared via Instagram, Twitter posts, etc.) but fundamentally include some aspect of an online social media contribution from an individual user and a location associated with it. Studies that examine spatial patterns in geosocial data usually make the implicit assumption that what people post in their social media is partly a reflection of their experience in physical place-time; for example, imbuing the locational expression of these posts with some place-based meaning (Hauthal and Burghardt, 2016). To our knowledge, there is little or no research that supports this assumption. Further, while all digital interactions occur in physical places, only a small fraction have this information recorded (e.g., Morstatter et al. 2013).

Social media platforms encode and store people's online exchanges in granular and detailed digital representations. For users of these platforms, these online tools provide 


\section{A Unified Ecological Framework for Studying Effects of Digital Places on Well-being}

convenient ways to interact with friends and family, find services, express themselves, generally define their online identity, and bolster their social capital. There is potential value for studies of well-being in exploring the content of these platforms for better understanding the behaviour of individuals, their social networks, and their movements in urban environments (Ellison et al. 2007; Larsen et al. 2015; Hawelka et al. 2014). As well, researchers interested in public health and urban planning have begun to explore the utility of combining the geographic data with the personal content embedded in the social media data itself to study human subjects (e.g., Ghosh and Guha 2013). This content, such as Tweets and posts on Instagram and Facebook, often contains information describing people's experiences in specific locations (whether it be about those locations or not).

The application of geolocated Twitter for public health surveillance has increased in recent years. For example, Grubener et al. (2017) provided a combined semantic - spatial analysis of georeferenced Tweets in the wake of terror events in Paris in November, 2015. This analysis was able to identify and monitor spatial clusters of emotions expressed on Twitter, such as fear and sadness. Many have also cited the potential value of geosocial data to capture more personalized aspects of places such as activities, feelings, and events (e.g., Elwood 2008; Feick and Robertson, 2015); which may be important for place and well-being studies (Chen and Yang 2014).

\subsubsection{Making sense of digital places}

In order to understand place effects using geosocial media data, it is necessary to estimate two latent constructs (shaded boxes) as outlined in Figure 1: the hidden internal state of the individual (which may be an emotional state, a behaviour, an intention) and the 'place' associated with that expression; both of which vary by individual. Most analyses of geosocial data have tended to focus on the analysis of internal state with semantic analysis of the text (i.e., a symbolic representation); and the analysis of place via the location references attached 


\section{A Unified Ecological Framework for Studying Effects of Digital Places on Well-being}

to the Tweets (i.e., geographic coordinates). We consider the content of a geosocial media post the symbolic representation (e.g., video content; voice recording, text data); and the geographic metadata associated with it the locational references (e.g., geographic coordinates, neighbourhood; postal code). There is uncertainty across and within individuals in the relationship between internal state and its expression in social media; as well as the location coordinates and the definition of place. Both of these latent constructs are individual-specific; the relations expressed by the solid arrows in Figure 1 will vary by individual. For example, one person may use the phrase 'this is unbelievable' in a positive sense, whereas others may use it in a negative sense. The symbolic representation also has a dependency on place, as the same expression may have different meaning in different contexts. Similarly, for estimating place from location references (e.g., geographic coordinates); one's most frequently Tweeted location might be their home, whereas for another it might be their work.

Figure 1 Schematic of relations between observed data (white boxes) and latent variables (shaded boxes) components of geosocial media analysis of health.

The representation of place within geographic information systems (GIS) has been recognized as a core need since the inception of GIS, yet still has not been fully realized. Competing models for the representation of place from VGI and geosocial media have included aggregating colloquial descriptions of specific regions or locales and mapping their boundaries. As these descriptions are individual, they may also give rise to differences in location references (dotted arrows in Figure 1). Hollenstein et al. (2010) provides a classic example; recording Tweets using the term 'downtown' in the USA and mapping their distribution (see Shelton et al. 2015 for a similar example). More sophisticated topic modelling approaches have been developed to do this type of analysis dynamically based on scale-dependent modelling and 
A Unified Ecological Framework for Studying Effects of Digital Places on Well-being

visualization of geolocated Tweets (Martin and Schuurman 2017). Deriving place representations from geosocial media is analogous to selecting units for mapping neighbourhoods in traditional heath geography research. As such, we will briefly review some recent research on mapping places from geosocial data.

Inductive approaches to place representation based on geosocial data tend to focus on aggregate spatial patterns to derive shared definitions of place, rather than specific instances of place locales. Robertson et al. (2017) provided a spatial clustering-based method for delineating home, work, and 'other' places on an individual basis from Tweets. Similar approaches by Huang et al. (2017) and Robertson et al (2017) use space-time clustering and activity-based models of human movement to derive individual places. These types of individual-based models of place using geosocial data can reflect the range of groups and geographic activity patterns within a population of social media contributors better than aggregate approaches where these differences are often masked. While these patterns may not be truly representative of urban communities at large, they provide a basis for contextualizing the interactions between place and individuals in the sample.

Deductive approaches for modelling place focus on specifying ontologies that describe the properties and relationships of places. Vasardani and Winter (2016) describe fifteen properties derived from Alexander (2002) pertaining to places, including levels of scale, boundaries, and gradients, among others. These properties can then be used to describe and parameterize place-representations. Alternatively, other approaches to representation of place consider the functional characteristics of places as central to their definition. Kuhn (2005) notes that people tend not to refer to places by a collection of their properties, but rather through what they enable people to do. According to Curry (1996), places are human constructions derived through activities such as naming, categorizing, symbolizing, narrating, and acting in. Building on these ideas in the context of GIS models of place, Jordan et al. (1998) propose a model of 
place based on Gibson's (1979) notion of affordances; those aspects of the environment that create opportunities for activities (i.e., that which they afford the user to do). These affordances are measurable and specific to the individual; and may vary by the types of interaction with objects in the environment and other individuals (Kuhn 1996). At a more general level, this model of place suggests that places are defined for an individual by the things and experiences that those locales create for them, and these are partially socially mediated.

These inductive and deductive models of place are not necessarily mutually exclusive. Both activities and locations can be derived from geosocial media in an attempt to model place directly. This is analogous to using both the solid and dotted arrows in Figure 1 to define place. However, whereas formal models of place recognize that individuals' perceptions, capabilities, and intentions are central to understanding their construction of place in a given context; estimating these parameters from social media data remains a research challenge.

\section{A Unified Ecological Framework for Place Effects on Well-being}

The key questions that underpin our action-oriented conceptual framework are twofold: "How does our use of digital places within physical places shape our well-being?", and relatedly, "How can interventions within and across these places potentially contribute to promoting wellbeing and reducing health disparities". To facilitate research about place effects on well-being using geosocial data, we offer a conceptual framework (Figure 1) that draws on ecological systems theory (e.g., Bronfenbrenner, 1977) to organize interactions occurring in specific digitalphysical places. While others have used ecological systems frameworks to study the role of contexts on child development, we propose a framework focused on the role of various interactions within and across places on general well-being of all populations. This framework acknowledges the reciprocal and dynamic relationship that people have with their places over time. Like other ecological systems frameworks, we intend to highlight the nesting and relative proximity to individuals of various the interactions included. In this framework, the well-being of 


\section{A Unified Ecological Framework for Studying Effects of Digital Places on Well-being}

individuals and, by extension, communities of people, exists in interaction with both social and built-natural characteristics of physical and digital places.

In our model, depicted in Figure 1, we position an individual person in the middle, with levels of digital and physical place interactions extending upward and downward, respectively. Interactions in digital places are conditional on interactions with specific digital platforms used, while those related to physical places are contingent on interactions with the specific built and natural characteristics of surrounding physical environments. On the right side of the model, lines are used to indicate how digital place interactions are also contingent on interactions with surrounding physical places, and vice versa. Finally, all interactions should be understood in the context of macro-social interactions, which contain physical and digital places, while also sometimes being linked to specific places (e.g., if a particular government has laws that strongly marginalize LGBTQ+ people, it may contribute to social stigma and heighten microaggressions experienced in both physical and digital place interactions for LGBTQ+ people). To give readers a deeper understanding of the elements and implications for place interactions, we have annotated the description of the framework with a running example of how the well-being of firsttime low-income mothers could be influenced by their interactions in physical and digital places.

Figure 2. A Unified Ecological Framework for Place Effects on Well-being

\section{1 Person}

The static and dynamic characteristics of persons, such as their demographics (e.g., age), history, personality (e.g., strong sense of community) (Talò, Mannarini \& Rochira, 2014), identity (e.g., gender), and social class (e.g., low income), influence placemaking and the effect of places on well-being in myriad ways. People also have unique collections of activity modes 
(e.g., residence, work, errands, leisure, study, care) that determine the physical and digital places they interact with over time. For example, Luu (2015) described how some women work to conceal their gender in online forums in an effort to maintain authority or avoid harassment. Finally, people have a variety of reasons for engaging in digital platforms that are related to wellbeing. For example, Lupton (2018) describes how individuals engage in "self-surveillance" to develop better self-knowledge and/or self-optimisation by using digital platforms to collect information about themselves.

In our example, we focus on first-time expectant mothers of low income. In many Western European and North American settings, this population experiences a disproportionate burden of both illness during pregnancy (Monte \& Ellis, 2012) and adverse birth outcomes (Shankardass et al, 2011), which makes them an important focus of public health intervention (Bowden \& Manning, 2016; Shoreditch Trust, 2017). This population are also more likely to be teenagers (Rotermann, 2007), socially isolated (Dominguez \& Watkins, 2003), have a personal and inter-generational history of poverty (Friedrichs \& Blasius, 2003; Smith \& Elander, 2006), and likely face barriers in accessing health care services (Loveland Cook, Selig, Wedge \& Gohn-Baube,1999); all of which we draw on below in our descriptive example to explore implications of place interactions for well-being. Finally, there may be a variety of reasons and ways that first-time expectant mothers of low income use and are prevented from using digital platforms. For example, first time mothers may have specific questions about their pregnancy that they satisfy through apps like Pregnancy +; younger individuals may be more likely to already use social networks like Facebook before pregnancy and rely on their friends to gather knowledge; while less wealthy individuals may be less likely to afford paid apps.

\subsection{Physical place}

Depending on their changing modes of activity over time, people will regularly and irregularly use a range of physical places, comprised of different built and natural characteristics. A large 
body of work identifies impacts on well-being of the non-human elements of our physical settings. Macintyre et al (2002) summarize several such pathways including "physical features of the environment shared by all residents in a locality" (p.131), the "availability of healthy environments at home, work and play" (Ibid.), and "services provided, publicly or privately to support people in their daily lives" (Ibid.). Mothers of lower income and mothers in single parent families are more likely to reside in neighbourhoods with less access to health and social services in some settings (e.g., Heaman et al, 2007).

The human context of physical settings includes meso-social interactions that occur in the context of social relations that can help or hinder well-being. In their framework, Macintyre et al (2002) describe how collective social functioning shapes well-being in local areas, including through "social-cultural features of an area" (p.131), "the reputation of an area" (Ibid.), and "services provided, publicly or privately to support people in their daily lives" (Ibid.), which also have a social component in terms of service delivery and appropriateness, for example. So, for example, social norms, criminal and charitable activities, and social composition can all influence place interactions in physical settings. In the Hackney borough of London, the Shoreditch Trust (a charitable organization) facilitates a peer mentoring program for socially isolated and otherwise vulnerable pregnant women called Bump Buddies, which provides social and informational support during what can be a very stressful period of some women's lives (Bowden \& Manning, 2016; Shoreditch Trust, 2017). Findings from Weaver et al (2008) indicate how the stressfulness of the social context in the neighbourhoods of pregnant women who are regular smokers explains a significant amount of the length into pregnancy that these women smoke, and the total number of cigarettes smoked.

Micro-social interactions in physical settings include the direct, inter-personal relations persons have in the context of their home, work, leisure, care and other settings that determine well-being. For example, the experience of social support (Uchino, Cacioppo \& Kiecolt-Glaser, 
1996) and intimate partner violence (Campbell, 2002) are both interpersonal processes that have a strong impact on well-being. Foreign-born U.S. Hispanic women of lower socioeconomic status experience better than expected birth outcomes (Flores, Simonsen, Manuck, Dyer \& Turok, 2012), which some argue may be mediated by stronger social support these women experience in ethnic enclaves (Gallo et al, 2015). For other women of low income, perinatal health is generally found to be relatively poor. In urban settings, low-income mothers sometimes have social networks that are "localized, insular, and sometimes draining" (Domínguez \& Watkins, 2003; p. 111), while the social networks of teenage mothers appears to limit information and opportunities (Fernández-Kelly, 1995), which can both hinder upward social mobility.

\subsection{Digital place}

Digital platforms include the various interactive places we inhabit online, such as Twitter, Facebook or Linkedln. These platforms are built by the developers and shaped by users. They may be used for various activities, including personal and professional purposes.

As noted above, different social media platforms affect our well-being in various ways. Social media platforms can be viewed as distinct places that shape how people interact with the platforms and other users. For example, DeVito, Birnholtz and Hancock (2017) describe how the self-presentation processes of social media users systematically vary by platform. Drawing on affordance theory, van Dijck (2013) noted that Facebook facilitates more personal selfpresentation while Linkedln necessitates more professional ways of presenting one's self. Erickson (2010) argued that Twitter's design encouraged more straightforward broadcasting, sometimes about specific places, which facilitated communal bonds more reflective of a "common geographical territory" (p.1204); whereas the social media Jaiku was better structured to facilitate threaded conversations that relied less on location. Davenport and colleagues (2013) observed differences in how younger and older narcissists preferred using Twitter and 
A Unified Ecological Framework for Studying Effects of Digital Places on Well-being

Facebook over other social media, respectively; and how platform differences helped to explain such differences (e.g., Twitter offering a more direct platform for micro-blogging, while Facebook offers others ways to display narcissistic motives). Papacharissi (2009) examined architectural differences in the public/private balance of social networks on different platforms and found, for example, that the relatively public nature of Facebook profiles (compared to Linkedln and ASmallWorld) was correlated with looser behavioural norms, among other differences.

These platform-level characteristics; governed by opaque developer modes and practices, may both reflect and shape health outcomes. In the context of maternal health, De Choudhury showed how using social media-derived data from shared Facebook activity of new mothers increased prediction of post-partum depression by 77\% (De Choudhury et al. 2014). Specifically, social isolation identified through reduced use of social media was related to increased risk of post-partum depression. The specific design features and characteristics of platforms that shape and orient micro and meso-scale relations for new mothers can be seen as the digital earth upon which interactions depend; in an analogous way that physical places can influence social relations in the physical world.

Meso-social interactions in digital platforms involve interactions at a broader social level than a specific person, where the user is potentially impacted by a wide range of information, opinions, perspectives, and content that is posted without having a direct interaction with the person doing the posting. Some people share content and information about themselves for others to view and enable what Marwick (2012) terms "social surveillance", where people watch each other on digital platforms as a way of forming or maintaining social relationships. There are also different social norms on different platforms, reflected by differences in how strictly speech and other content is policed. Thus, the well-being of people can be affected through what has been referred to as passive use of social media (e.g., Verduyn et al, 2015; Appel, Gerlach \& Crusius, 2016), such as monitoring the activity of others (e.g., observing the tweets, status 
updates or comments of others) without posting any of one's own content in response to the monitored activity. This type of social media activity has been termed positively as "listening" (Crawford, 2009) and with a more negative connotation as "lurking". Passive activity can improve well-being by facilitating information gleaning about health promotion, for example. However, some evidence suggests that passive use of Facebook (e.g., liking content on Facebook) can be harmful (Verduyn et al, 2015); where passive use appears to foster social comparisons and feelings of envy in users (Appel, Gerlach \& Crusius, 2016). Evidence also indicates how indirectly observing activities of other users on Facebook can determine wellbeing, and how experiences online can shape interaction in real life. For example, Rubin \& McClelland (2015) describe the stress experienced by young women who are sexual minorities working to maintain a "virtual closet" (p.521), including as they grapple to negotiate online and real-life friendships with people who exhibit homophobia as observed in these women's newsfeeds, and as they experience other types of microaggressions on Facebook. For example, Figure 3 demonstrates how awareness raising about the Bump Buddies program is facilitated through observing ads on Facebook.

Figure 3. A public Facebook post from community-based organization (Hackney Real Nappy Network) about the Bump Buddies program.

Micro-social interactions include those activities in which people directly interact with others, or at least an attempt to engage others in a kind of localized social interaction. This type of online interaction is characterized by active use of social media (e.g., writing tweets and status updates, commenting and responding to others), and can influence well-being in a variety of ways. For example, one recent study found that active use of Facebook (e.g., communicating with others in comments or private messages) can have positive effects on well-being, possibly 


\section{A Unified Ecological Framework for Studying Effects of Digital Places on Well-being}

by fostering feelings of social connectedness and social capital for some users (Burke \& Kraut, 2016; Ellison, Steinfield \& Lampe, 2007). It also seems obvious that social media platforms can offer people a way of directly asking their virtual community for help or advice, as needed; but also, that different platforms make it easier or more difficult for strangers to send harassing messages to persons. McDaniel et al (2012) found that the frequency of blogging -- an active social media activity -- was correlated with the perception of social support and higher maternal well-being among new mothers.

\subsection{Macro-social interactions}

Macro-social interactions include how persons are engaged in and influenced by political and economic processes, formal policies, and broad cultural norms that structure all levels of interaction in physical and digital places. There are many factors to consider that can influence well-being such as criminal laws, welfare state policies, and workplace health and safety policies. In our example, young, new, low-income mothers who live in societies that do not have parental leave benefits may be more likely to be working shortly after childbirth. In another example, in the United Kingdom, changes in 2012 to the NHS via the 2012 Health and Social Care Act were intended to shift public funding from more patient care from hospitals towards more community-based care, such as Bump Buddies; but appear to have actually increased specialist care, while not impacting hospitalizations (Lopez Bernal, Lu, Gasparrini, Cummins, et al, 2017). Thus, community-based programs like Bump Buddies, do not appear to have been scaled-up by this policy shift. In the digital environment, examples include factors such as terms of service agreements for social media, and laws and policies about social media use (for example, workplace policies). In particular, well-being can be influenced by the presence or absence of cyberbullying laws that may deter assault in digital platforms. In Canada, Bill C-13 (Protecting Canadians from Online Crime Act) makes it illegal to distribute images of a person without consent. The well-being of new mothers (and their off-spring) may be influenced by how 


\section{A Unified Ecological Framework for Studying Effects of Digital Places on Well-being}

guidance about screen time around children by medical experts (Radesky \& Christakis, 2016) influences how the mother uses social media.

\subsection{Fuzzy separations and transcendent linkages of digital and physical places}

The dotted line separating factors from the digital and physical environments represents the vague, undefined separation between these two aspects of people's social worlds. That is, it is important to remember that people sometimes do not have a clear delineated separation between their physical and digital places. Lohse (2013) demonstrates how ads such as the one in Figure 3 can be used to recruit low-income women to online health education projects. Place interactions in this online learning path will still be occurring in a physical place, so learning is then imbued with all of the characteristics (physical and macro-social) characterizing that place; and defining that person's relationship/experience of the place (the fusion of the physical and digital places).

Similarly, the lines linking factors across physical and digital places represent interactions that transcend these environments. For example, digital social networks can overlap across platforms and with their physical social networks; so a person might follow another person on Instagram, be their friend on Facebook and spend time with them in real life.

\section{Discussion and call for research}

There is growing interest in using geosocial data in health research and urban health/social planning interventions, which creates an opportunity for health geographers and others to foster place-based approaches that extend the discourse about physical place and well-being. We have presented an ecological framework for a unified approach that offers a series of interactions and inter-relationships on which to connect digital places to physical places. This framework is not intended to explain all of the ways that digital platforms affect well- 
being; rather, given the lack of rich theory and evidence about how and why digital platforms matter, it is a heuristic for using place theory to study effects on well-being. This can help to understand what different geosocial media can tell us about how the use of digital platforms over space and time, and which related physical environments influence well-being; and then identify variables and data to directly study specifically how digital and physical places influence well-being using an ecological systems approach.

For example, geosocial media can be used to study the effects of physical, rather than digital, places on well-being since metadata can include expressions and location (e.g., GPS coordinates). There are many approaches to such a question, and this framework can help to identify the relevance of certain metadata (e.g., location) and physical place interactions. In one case, a study might aim to investigate the physical or social environment of social media use in a direct and momentary way by linking expressions to GPS coordinates. Here, interaction in the physical place are of primary interest, while digital place interactions may be less important for examining well-being. In another case, a study might collect relevant expressions using tags of places (e.g., \#Hamilton) as indicators of positive or negative experiences (e.g., "I love the diversity of \#Hamilton!", compared to "The potholes along James St. N are out of control! \#Hamilton). Here, GPS coordinates can help indicate whether expressions are related to direct or indirect (e.g., future, past, never) experiences, and therefore, the utility of data about physical places.

Knowledge about place effects on well-being has found many applications; for example, findings are sometimes integrated into healthy communities and cities via design elements (e.g., public space, transport and transportation efficiencies) (Rydin et al., 2012; Barton and Tsourou, 2013). Thus, the framework also has instrumental value for identifying elements that may serve as entry points for place-based interventions. Grzywacz and Fuqua (2000) discuss how social ecology theory can be applied by health professionals to improve health by identifying salient 


\section{A Unified Ecological Framework for Studying Effects of Digital Places on Well-being}

"linkages" and "leverage points", which may be indicated in our framework by the different levels of interaction and their inter-relationships, respectively.

This framework may apply to an array of digital platforms to understand how digital place effects vary by platform type. This includes platforms that may be used to explicitly link to physical places, such as: (a) websites describing or integrating physical places, like a museum, restaurant, mall, gallery, tourist destination; (b) representations of physical places in digital realms, such as how Google Street View and user-contributed photographs help immerse uses into specific physical places; and (c) social media content, which may contain GPS metadata or some user-contributed (e.g., written or photographed) representation of physical places, or of the digital platforms itself. There are components of digital platforms that are not meant to be and may not be tied to physical places, such as: (d) virtual worlds and video games with virtual environments of their own; and (e) social media posts without metadata or connected in other ways to physical place.

In our framework, we conceptualize social interactions in digital platforms using language consistent with physical environments (i.e., micro-social and meso-social) for clarity and consistency. This approach makes the framework more transparent and easier to grasp; although, it is not evident that the interactions or impacts of relationships in and from these environments are the same. It is likely that the types of support or stressors related to interactions in digital and physical places are at least qualitatively different. For example, just because one has a large number of Facebook friends and receives a lot of likes on their posts, they may not be a "popular" or "well-liked" person in the non-digital realm. In general, more work is needed to understand how well concepts of places developed about physical settings apply to digital platforms. This place-based framework is sensitive to the same problems of scale and boundaries that other spatial geography is. Scale of analysis can break up units in ways that misses the right scale for social interaction over space; and thus place effects (Logan, 2012). 


\section{A Unified Ecological Framework for Studying Effects of Digital Places on Well-being}

Although the current framework offers a tool for studying geosocial data, more work is needed to understand who is producing (and is excluded from) this information in different settings, and how this use relates to the places and spaces impacting their health behaviours and outcomes. Geosocial data are limited in their representativeness of social media users in several ways that vary from place to place. The general lack of collection of location data limits inclusion to around 5\% of Tweets, for example (Morstattter et al. 2013); and this level varies over time. For example, recent revelations about how extensively Facebook has been sharing user information (Petrescu \& Krishen, 2018) influences privacy concerns and may lead to a temporary or long-term decline in how users are willing to share information such as location.

Other issues of representativeness arise from the so-called digital divide, in which researchers have pointed to people who have higher income levels also tend to be those with internet access, or high-speed internet access (e.g., Haight, Quan-Haase \& Corbett, 2014). The digital divide may lead to under-representation of the expressions of populations bearing the greatest burden of illness within a society -- those in lower income brackets and without or with less internet access. Yet, people of lower incomes also report slightly greater uses of SNS than those of higher income, and other data suggests that some marginalized populations may be more likely to use such technology as a means to overcome social isolation (e.g., African American college students; recent immigrants in Canada [Haight, Quan-Haase \& Corbett, 2014; Junco, Merson \& Salter, 2010]). More nuanced analysis may therefore move beyond simple access to examine how particular strata of society differentially use these digital platforms; research which the framework introduced here may supplement.

Another limitation of geosocial data is that representation of self on social media networks is widely regarded as performative in nature (Hogan 2010); people selectively share samples of one's internal beliefs, perceptions, feelings, behaviours, and activities. The partial selection of these is designed as part of an identity construction and maintenance regime 


\section{A Unified Ecological Framework for Studying Effects of Digital Places on Well-being}

(Marwick 2013). This active identity construction carries over to geosocial data as well, through the selection of which places warrant posting and/or checking in on geographically referenced social media networks. Schwartz and Halegoua (2015) describe this selection through the framework of the spatial self, which examines the presentation of one's identity through geographic traces of physical (i.e., real world) activity. As described by Saker (2017) the spatial self 'involves people actively thinking about the spaces they frequent, what they might present about their identity, and if this fits in with their on-going narratives.'

In light of these recent understandings of how and why people interact with social media, there is a need for more theoretically informed approaches to the analysis of geosocial data. In particular, new models of how place is produced through digital platforms and interactions and how these forms of production relate to more traditional concepts of place are needed. Our focus on how interactions with digital platforms, physical environments and social factors within is a heuristic for structuring research on how digital and physical places jointly influence wellbeing. Clearly a range of theory and evidence from disciplines as diverse as information sciences, geography, sociology, psychology, epidemiology, and neurobiology will be useful for explaining how our expanding use of digital and online networks impacts well-being, and how we can use digital platforms to improve well-being. 
A Unified Ecological Framework for Studying Effects of Digital Places on Well-being

\section{References}

Alexander, C. (1979). The Timeless Way of Building. New York: Oxford University Press.

Alexander, C. (2002). The Phenomenon of Life: Nature of Order, Book 1: An Essay on the Art of Building and the Nature of the Universe: Routledge.

Appel, H., Gerlach, A. L., \& Crusius, J. (2016). The interplay between Facebook use, social comparison, envy, and depression. Current Opinion in Psychology, 9, 44-49.

Barton, H., \& Tsourou, C. (2013). Healthy urban planning. New York: World Health Organization.

Bernal, J. A. L., Lu, C. Y., Gasparrini, A., Cummins, S., Wharham, J. F., \& Soumerai, S. B. (2017). Association between the 2012 Health and Social Care Act and specialist visits and hospitalisations in England: A controlled interrupted time series analysis. PLoS Med, 14(11), e1002427.

Bernard, P., Charafeddine, R., Frohlich, K., Daniel, M., Kestens, Y., \& Potvin, L. (2007) Health inequalities and place: a theoretical conception of neighbourhood. Soc Sci Med, 65(9), $1839-1852$.

Bowden, J., \& Manning, V. (2016). Health Promotion in Midwifery: Principles and Practice (3 ed.): CRC Press.

Bronfenbrenner, U. (1977). Toward an experimental ecology of human development. American Psychologist, 32(7), 513-531.

Brownstein, J. S., Freifeld, C. C., Reis, B. Y., \& Mandl, K. D. (2008). Surveillance Sans Frontières: Internet-Based Emerging Infectious Disease Intelligence and the HealthMap Project. PLoS Med, 5(7).

Burke, M., \& Kraut, R. E. (2016). The relationship between Facebook use and well-being depends on communication type and tie strength. Journal of Computer-Mediated Communication, 21(4), 265-281. 
A Unified Ecological Framework for Studying Effects of Digital Places on Well-being

Burke, M., Marlow, C., \& Lento, T. (2010). Social network activity and social well-being. Paper presented at the $\mathrm{CHI}$ '10 Proceedings of the SIGCHI conference on human factors in computing systems, Atlanta, Georgia, USA.

Campbell, J. C. (2002). Health consequences of intimate partner violence. The Lancet, 359(9314), 1331-1336.

Cebeillac, A., Eric, D., \& Huraux, T. (2016). Where? When? And how often? What can we learn about daily urban mobilities from Twitter data and Google Map in Bangkok (Thailand) and what are the perspectives for Dengue studies? Paper presented at the Actes du 15e colloque du GT Mobilités Spatiales, Fluidité Sociale (MSFS).

Chen, X., \& Yang, X. (2014). Does food environment influence food choices? A geographical analysis through "tweets". Applied Geography, 51, 82-89.

Choi, N. G., \& DiNitto, D. M. (2013). Internet use among older adults: association with health needs, psychological capital, and social capital. Journal of Medical Internet Research, 15(5).

Crawford, K. (2009). Following you: Disciplines of listening in social media. Journal of Media \& Cultural Studies, 23(4), 525-535.

Croitoru, A., Crooks, A., Radzikowski, J., \& Stefandis, A. (2013). Geosocial gauge: a system prototype for knowledge discovery from social media. . International Journal of Geographical Information Science, 27(12), 2483-2508.

Cummins, S., Curtis, S., Diez-Roux, A. V., \& Macintyre, S. (2007). Understanding and representing 'place' in health research: A relational approach. Social Science \& Medicine, 65(9), 1825-1838.

Curry, M. R. (1996). The Work in the World: Geographical Practice and the Written Word Minneapolis, Minnesota: University of Minnesota Press. 
A Unified Ecological Framework for Studying Effects of Digital Places on Well-being

Davenport, S. W., Bergman, S. M., Bergman, J. Z., \& Fearrington, M. E. (2014). Twitter versus Facebook: Exploring the role of narcissism in the motives and usage of different social media platforms. Computers in Human Behavior, 32, 212-220.

de Oliveira, T. H. M., \& Painho, M. (2015). Emotion \& stress mapping: Assembling an ambient geographic information-based methodology in order to understand smart cities. Paper presented at the 10th Iberian Conference on Information Systems and Technologies.

Dear, M. J. \& Wolch, J. R. (1987). Landscapes of Despair: From Deinstitutionalization to Homelessness. Princeton, New Jersey: Princeton University Press.

Deters, F. G., \& Mehl, M. R. (2013). Does posting Facebook status updates increase or decrease loneliness? An online social networking experiment. Social psychological and personality science, 4(5), 579-586.

Devito, M. A., Birnholtz, J., \& Hancook, J. T. (2017). Platforms, people, and perception: Using affordances to understand self-presentation on social media. Paper presented at the SCW 2017 - Proceedings of the 2017 ACM Conference on Computer Supported Cooperative Work and Social Computing, Portland, United States.

Dominguez, S., \& Watkins, C. (2003). Creating networks for survival and mobility: Social capital among African-American and Latin-American low-income mothers. Social problems, $50(1), 111-135$.

Dupéré, V. \& Perkins, D. D. (2007). Community types and mental health: a multilevel study of local environmental stress and coping. Am J Community Psychol, 39(1-2), 107-119.

Eberst, R. M. (1984). Defining Health: A Multidimensional Model. J Sch Health, 54(3), 99-104.

Ellison, N. B., Stedman, R. C., \& Lampe, C. (2007). The Benefits of Facebook "Friends": Social Capital and College Students' Use of Online Social Network Sites. Journal of ComputerMediated Communication, 12(4), 1143-1168.

Elwood, S. (2008). Volunteered geographic information: future research directions motivated by critical, participatory, and feminist GIS. GeoJournal, 72(3), 173-183. 
A Unified Ecological Framework for Studying Effects of Digital Places on Well-being

Erickson, I. (2010). Geography and Community: New Forms of Interaction Among People and Places. American Behavioral Scientist, 53(8), 1194-1207.

Feick, R., \& Robertson, C. (2014). A multi-scale approach to exploring urban places in geotagged photographs. Computers, Environment and Urban Systems, 53, 96-109.

Feick, R., \& Robertson, C. (2015). Identifying locally- and globally-distinctive urban place descriptors from heterogeneous user-generated content. In F. Harvey \& Y. Leung (Eds.), Advances in Spatial Data Handling and Analysis (pp. 51-63): Springer International Publishing.

Fergie, G., Hunt, K., \& Hilton, S. (2016). Social media as a space for support: young adults' perspectives on producing and consuming user-generated content about diabetes and mental health. . Social Science \& Medicine, 170, 46-54.

Fernández-Kelly, M. P. (1995). Social and Cultural Capital in the Urban Ghetto: Implications for the Economic Sociology of Immigration. In Portes (Ed.), The Economic Sociology of Immigration: Essays on Networks, Ethnicity, and Entrepreneurship (pp. 213-247). New York: Russell Sage.

Flores, M. E. S., Simonsen, S. E., Manuck, T. A., Dyer, J. M., \& Turok, D. K. (2012). The "Latina Epidemiologic Paradox": Contrasting Patterns of Adverse Birth Outcomes in U.S.-Born and Foreign-Born Latinas. Women's Health Issues, 22(5), e501-e507.

Friedrichs, J., \& Blasius, J. (2003). Social Norms in Distressed Neighbourhoods: Testing the Wilson Hypothesis. Housing Studies, 18, 807-826.

Gallo, L. C., Fortmann, A. L., McCurley, J. L., Isasi, C. R., Penedo, F. J., Daviglus, M. L., . . . Carnethon, M. R. (2015). Associations of Structural and Functional Social Support with Diabetes Prevalence in U.S. Hispanics/Latinos: Results from the HCHS/SOL Sociocultural Ancillary Study. Journal of Behavioral Medicine, 38(1), 160-170.

Gesler, W. M. (1992). Therapeutic landscapes: Medical issues in light of the new cultural geography. Soc Sci Med, 34(7), 735-746. 
A Unified Ecological Framework for Studying Effects of Digital Places on Well-being

Ghosh, D., \& Guha, R. (2013). What are we 'tweeting' about obesity? Mapping tweets with topic modeling and Geographic Information System. Cartography and Geographic Information Science, 40(2), 90-102.

Gibson, J. J. (1979). The Theory of Affordances. In J. J. Gieseking, W. Mangold, C. Katz, S. Low, \& S. Saegert (Eds.), The People, Place, and Space Reader. New York: Routledge.

Gibson, L., \& Hanson, V. L. (2013). Digital motherhood: how does technology help new mothers? Paper presented at the $\mathrm{CHI}$ '13 Proceedings of the SIGCHI Conference on Human Factors in Computing Systems, Paris, France.

Gieryn, T.F. (2000). A space for place in sociology. Annu Rev Sociol, 26, 463-496.

Gruebner, O., Sykora, M., Lowe, S. R., Shankardass, K., Trinquart, L., Jackson, T., ... Galea, S. (2016). Mental health surveillance after the terrorist attacks in Paris. International Journal of Health Geographics, 387(10034), 2195-2196.

Grzywacz, J. G., \& Fuqua, J. (2000). The social ecology of health: leverage points and linkages. Behavioral Medicine, 26(3), 101-115.

Haight, M., Quan-Haase, A., \& Corbett, B. A. (2014). Revisiting the digital divide in Canada: the impact of demographic factors on access to the internet, level of online activity, and social networking site usage. Information, Communication \& Society, 17(4), 503-519.

Hanson, C. L., Burton, S. H., Giraud-Carrier, C., West, J. H., Barnes, M. D., \& Hansen, B. (2013). Tweaking and Tweeting: Exploring Twitter for Nonmedical Use of a Psychostimulant Drug (Adderall) Among College Students. Journal of Medical Internet Research, 15(4), e62.

Hauthal, E., \& Burghardt, D. (2016). Mapping Space-Related Emotions out of User-Generated Photo Metadata Considering Grammatical Issues. The Cartographic Journal, 53(1), 7890. 
A Unified Ecological Framework for Studying Effects of Digital Places on Well-being

Hawelka, B., Sitko, I., Beinat, E., Soboleysky, S., Kazakopoulos, P., \& Ratti, C. (2014). Geolocated Twitter as proxy for global mobility patterns. Cartography and Geographic Information Science, 41(3), 260-271.

Heaman, M. I., Green, C. G., Newburn-Cook, C. V., Elliott, L. J., \& Helewa, M. E. (2007). Social Inequalities in Use of Prenatal Care in Manitoba. Journal of Obstetrics and Gynaecology Canada, 29(10), 806-816.

Hogan, B. (2010). The Presentation of Self in the Age of Social Media: Distinguishing Performances and Exhibitions Online. Bulletin of Science, Technology \& Society, 30(6), 377-386.

Hollenstein, L., \& Purves, R. S. (2010). Exploring place through user-generated content: Using Flickr tags to describe city cores. Journal of Spatial Information Science(1), 21-48.

Horan, T. A. (2001). Design Considerations for Integrating Electronic Space with Physical Place. Information Technology and the City, 37(144), 12-19.

Huang, X., Iliev, I. R., Lyubchich, V., \& Gel, Y. R. (2017). Riding down the Bay: Space-time clustering of ecological trends. Environmetrics, e2455.

Huppert, F.A. \& So, T.T.C. (2013). Flourishing Across Europe: Application of a New Conceptual Framework for Defining Well-Being. Soc Indic Res, 110(3), 837-861.

Jordan, T., Raubal, M., Gartrell, B., \& Egenhofer, M. J. (1998). An Affordance-Based Model of Place in GIS. Paper presented at the Eighth International Symposium on Spatial Data Handling, Vancouver, Canada.

Jorgensen, B., \& Stedman, R. C. (2001). Sense of place as an attitude: Lakeshore owners attitudes toward their properties. Journal of Environmental Psychology, 21, 233-248.

Junco, R., Merson, D., \& Salter, D. W. (2010). The effect of gender, ethnicity, and income on college students' use of communication technologies. Cyberpsychology, Behavior, and Social Networking, 13(6), 619-627. 
A Unified Ecological Framework for Studying Effects of Digital Places on Well-being

Kearns, R., \& Moon, G. (2002). From medical to health geography: novelty, place and theory after a decade of change. Prog Hum Geogr, 26(5), 605-625.

Keene, D. E. \& Padilla, M. B. (2010). Race, Class, and the Stigma of Place: Moving to "Opportunity" in Eastern lowa. Health Place, 16(6), 1216-1223.

Kelly, M. P. F. (1994). Towanda's Triumph: Social and Cultural Capital in the Transition to Adulthood in the Urban Ghetto. International Journal of Urban and Regional Research, 18(1), 88-111.

Kozuki, N., Lee, A. C. C., Silveira, M. F., Sania, A., Vogel, J. P., Adair, L., . . Child Health Epidemiology Reference Group (CHERG) Small-for-Gestational-Age-Preterm Birth Working Group1. (2013). The associations of parity and maternal age with small-forgestational-age, preterm, and neonatal and infant mortality: a meta-analysis. BMC Public Health, 13(3).

Krasnova, H., Wenninger, H., Widjaja, T., \& Buxmann, P. (2013). Envy on Facebook: A hidden threat to users' life satisfaction? Paper presented at the Proceedings of the 11th International Conference on Wirtschaftsinformatik (WI2013), Universität Leipzig, Germany.

Kuhn, W. (1996). Handling data spatially: Spatializating user interfaces. Paper presented at the Advances in GIS research II: Proceedings of the 7th International Symposium on Spatial Data Handling.

Kuhn, W. (2005). Geospatial semantics: why, of what, and how? Paper presented at the Journal on Data Semantics III.

Kwan, M. (2008). From oral histories to visual narratives: re-presenting the post-September 11 experiences of the Muslim women in the United States. Soc Cult Geo, 9, 653-669.

Larsen, M. E., Boonstra, T. W., Batterham, P. J., O'Dea, B., Paris, C., \& Christensen, H. (2015). We Feel: Mapping Emotion on Twitter. IEEE Journal of Biomedical and Health Informatics, 19(4), 1246-1252. 
A Unified Ecological Framework for Studying Effects of Digital Places on Well-being

Lengen, C., \& Kistemann, T. (2012). Sense of place and place identity: Review of neuroscientific evidence. Health and Place, 18(5), 1162-1171.

Logan, J. R. (2012). Making a place for space: Spatial thinking in social science. Annu Rev Sociol, 38, 1146.

Lohse, B. (2013). Facebook Is an Effective Strategy to Recruit Low-income Women to Online Nutrition Education. Journal of Nutrition Education and Behavior, 45(1), 69-76.

Louv, R. (2006). Last child in the woods: saving our children from nature-deficit disorder (1 ed.): Chapel Hill, NC : Algonquin Books of Chapel Hill.

Loveland Cook, C. A., Selig, K. L., Wedge, B. J., \& Gohn-Baube, E. A. (1999). Access Barriers and the Use of Prenatal Care by Low-Income, Inner-City Women. Social Work, 44(2), 129-139.

Lucas, K. (2012). Transport and social exclusion: Where are we now? . Transport Policy, 20, 105-113.

Luginaah, I. N., Taylor, S. M., Elliot, S. J., \& Eyles, J. D. (2002). Community reappraisal of the perceived health effects of a petroleum refinery. Social Science \& Medicine, 55(1), 4761.

Lupton, D. (2018). Digital Health: Critical and Cross-Disciplinary Perspectives. New York, NY: Routledge.

Luu, C. (2015). How to disappear completely: linguistic anonymity on the Internet. Retrieved from

Macintyre, S., Ellaway, A., \& Cummins, S. (2002). Place effects on health: how can we conceptualise, operationalise and measure them? Social Science \& Medicine, 55(1), 125-139.

Malecki, E. J. (2017). Real people, virtual places, and the spaces in between. Socio-Economic Planning Sciences, 58, 3-12. 
A Unified Ecological Framework for Studying Effects of Digital Places on Well-being

Martin, M. E., \& Schuurman, N. (2017). Area-Based Topic Modeling and Visualization of Social Media for Qualitative GIS. Annals of the American Association of Geographers, 107(5), 1028-1039.

Marwick, A. (2012). The Public Domain: Social Surveillance in Everyday Life. Surveillance \& Society, 9(4), 378-393.

Marwick, A. (2013). Online Identity. In J. Hartley, J. Burgess, \& A. Bruns (Eds.), Companion to New Media Dynamics (pp. 355-364). Malden, MA: Blackwell.

McDaniel, B., Coyne, S. M., \& Holmes, E. K. (2012). New Mothers and Media Use: Associations Between Blogging, Social Networking, and Maternal Well-Being. Maternal and Child Health Journal, 16(7), 1509-1517.

McHugh, K. E., \& Mings, R. C. (1996). The Circle of Migration: Attachment to Place in Aging. Annals of the Association of American Geographers, 86(3), 530-550.

Mitchell, L., Frank, M. R., Harris, K. D., Dodds, P. S., \& Danforth, C. M. (2013). The Geography of Happiness: Connecting Twitter Sentiment and Expression, Demographics, and Objective Characteristics of Place. PLoS Med, 8(5), e64417.

Mitchell, W. J. (1996). City of Bits. Cambridge, MA: MIT Press.

Moon, G. (1990). Conceptions of space and community in British health policy. Soc Sci Med, $30(1), 165-171$.

Montague, E., \& Xu, J. (2012). Understanding active and passive users: The effects of an active user using normal, hard and unreliable technologies on user assessment of trust in technology and co-user. Applied Ergonomics, 43(4), 702-712.

Monte, L. M., \& Ellis, R. R. (2014). Fertility of Women in the United States: 2012 Population Characteristics. Washington, DC: Census Bureau.

Morstatter, F., Pfeffer, J., Liu, H., \& Carley, K. M. (2013). Is the Sample Good Enough? Comparing Data from Twitter's Streaming API with Twitter's Firehose. Paper presented 
at the Proceedings of the Seventh International AAAI Conference on Weblogs and Social Media, ICWSM 2013, Cambridge, MA, United States.

Obar, J. A., \& Wildman, S. (2015). Social media definition and the governance challenge: An introduction to the special issue. Telecommunications Policy, 39(9), 745-750.

Papacharissi, Z. (2009). The virtual geographies of social networks: a comparative analysis of Facebook, Linkedln and ASmallWorld. New Media \& Society, 11(1-2), 199-220.

Pearce, K. E., \& Rice, R. E. (2013). Digital divides from access to activities: Comparing mobile and personal computer Internet users. Journal of Communication, 63(4), 721-744.

Petrescu, M. \& Krishen, A.S. (2018). Analyzing the analytics: data privacy concerns. J Market Anal, 6(2): 41-43.

Radesky, J., Christakis, D., Hill, D., Ameenuddin, N., Reid, C. Y. L., Cross, C., . . Swanson, W. S. (2016). Media and Young Minds. Pediatrics, 138(5).

Resch, B., Summa, A., Sagl, G., Zeile, P., \& Exner, J.-P. (2015). Urban emotions: Geo-semantic emotion extraction from technical sensors, human sensors and crowdsourced data. In G. Gartner \& H. Huang (Eds.), Progress in Location-Based Services 2014. Cham, Switzerland: Springer International Publishing.

Robertson, C., \& Feick, R. (2016). Bumps and bruises in the digital skins of cities: Unevenly distributed user-generated content across US urban areas. Cartography and Geographic Information Science, 4(3), 283-300.

Robertson, C., Feick, R., Sykora, M., Shankardass, K., \& Shaughnessy, K. (2017). Personal Activity Centres and Geosocial Data Analysis: Combining Big Data with Small Data. Paper presented at the The Annual International Conference on Geographic Information Science, Wageningen, The Netherlands.

Rotermann, M. (2007). Second or subsequent births to teenagers. Health Reports, 18(1), 39-42. 
A Unified Ecological Framework for Studying Effects of Digital Places on Well-being

Rubin, J. D., \& McClelland, S. I. (2015). 'Even though it's a small checkbox, it's a big deal': stresses and strains of managing sexual identity (s) on Facebook. Culture, health \& sexuality, 17(4), 512-526.

Rydin, Y., Bleahu, A., Davies, M., Dávila, J. D., Friel, S., De Grandis, G., . . Wilson, J. (2012). Shaping cities for health: complexity and the planning of urban environments in the 21st century. The Lancet, 379(9831), 2079-2108.

Saker, M. (2017). Foursquare and identity: Checking-in and presenting the self through location. New Media \& Society, 19(6), 934-949.

Schwartz, R., \& Halegoua, G. R. (2015). The spatial self: Location-based identity performance on social media. New Media \& Society, 17(10), 1643-1660.

Shakya, H. B., \& Christakis, N. A. (2017). Association of Facebook Use With Compromised Well-Being: A Longitudinal Study. American Journal of Epidemiology, 185(3), 203-211.

Shankardass K. (2012). Place-based stress and chronic disease: A systems view of environmental determinants. In P. O’Campo \& J.R. Dunn (Eds.), Rethinking Social Epidemiology: Towards a Science of Change. New York, NY: Springer Publishing Company.

Shankardass, K., Feick, R., Robertson, C., Shaughnessy, K., Sykora, M., Bang, F., ... Mistry, S. (2017). Stresscapes: Exploring landscapes of emotional stress using sentiment analysis of geo-social media. Paper presented at the International Medical Geography Symposium, Angers, France.

Shankardass, K., Jerrett, M., Milam, J., Richardson, J., Berhane, K., \& Mcconnell, R. (2011). Social environment and asthma: associations with crime and No Child Left Behind programmes. Journal of Epidemiology and Community Health, 65(10), 859-865.

Shankardass, K., O'Campo, P., Dodds, L., Fahey, J., \& Allen, V. M. (2011). Explaining inequalities in adverse perinatal outcomes for high and low income families in Nova 
A Unified Ecological Framework for Studying Effects of Digital Places on Well-being

Scotia. Paper presented at the 24th Annual Meeting of the Society for Pediatric and Perinatal Epidemiologic Research, Montreal, Canada.

Shankardass, K., O'Campo, P., Dodds, L., Fahey, J., Joseph, K. S., Morinis, J., \& Allen, V. M. (2014). Magnitude of income-related disparities in adverse perinatal outcomes. BMC Pregnancy and Childbirth, 14, 96.

Shaughnessy, K., Reyes, R., Shankardass, K., Sykora, M., Feick, R., Lawrence, H., \& Robertson, C. (2017). Using Geolocated Social Media for Ecological Momentary Assessments of Emotion: Innovative Opportunities in Psychology Science and Practice. Canadian Psychology/Psychologie canadienne, 2017.

Shelton, T., Poorthuis, A., \& Zook, M. (2015). Social media and the city: Rethinking urban sociospatial inequality using user-generated geographic information. Landscape and Urban Planning, 142(14), 198.

Shiffman, S., Stone, A. A., \& Hufford, M. R. (2008). Ecological momentary assessment. Annual Review of Clinical Psychology, 4, 1-32.

Shoreditch Trust. (2017) Bump Buddies. http://www.shoreditchtrust.org.uk/health-andwellbeing/bump-buddies/, Date accessed: January 30, 2018.

Smith, D. M., \& Elander, J. (2006). Effects of area and family deprivation on risk factors for teenage pregnancy among 13-15-year-old girls. Psychology Health and Medicine, 11(4), 399-410.

Squires, G. D. \& Kubrin, C. E. (2005). Privileged Places: Race, Uneven Development and the Geography of Opportunity in Urban America. Urban Stud, 42(1), 47-68.

Stefandis, A., Crooks, A., \& Radzikowski, J. (2013). Harvesting ambient geospatial information from social media feeds. GeoJournal, 78(2), 319-338.

Sykora, M., Jackson, T. W., O'Brien, A., \& Elayan, S. (2013). Emotive ontology: extracting finegrained emotions from terse, informal messages. . Paper presented at the IADIS 
A Unified Ecological Framework for Studying Effects of Digital Places on Well-being

International Conference Intelligent Systems and Agents 2013, ISA 2013,, Prague, Czech Republic.

Sykora, M., Robertson, C., Shankardass, K., Feick, R., Shaughnessy, K., Coates, B., .. . Jackson, T. W. (2015). Stresscapes: validating linkages between place and stress expression on social media. Paper presented at the Second International Workshop on Mining Urban Data, Lille, France.

Talò, C., Mannarini, T., \& Rochira, A. (2014). Sense of Community and Community Participation: A Meta-Analytic Review. Social Indicators Research, 117(1), 1-28.

Taylor, M., Wells, G., Howell, G., \& Raphael, B. (2012). The role of social media as psychological first aid as a support to community resilience building. Australian Journal of Emergency Management, 27(1), 20-26.

Trull, T. J., \& Ebner-Priemer, U. W. (2009). Using experience sampling methods/ecological momentary assessment (ESM/EMA) in clinical assessment and clinical research: introduction to the special section. Psychol Assess, 21, 457-462.

Uchino, B. N., Cacioppo, J. T., \& Kiecolt-Glaser, J. K. (1996). The relationship between social support and physiologial processes: A review with emphasis on underlying mechanisms and implications for health. Psychological Bulletin, 119(3), 488-531.

Van Dijck, J. (2013). 'You have one identity': performing the self on Facebook and Linkedln. Media, Culture \& Society, 35(2), 199-215.

Vasardani, M., \& Winter, S. (2016). Place Properties. In H. Onsrud \& W. Kuhn (Eds.), Advancing Geographic Information Science: The Past and Next Twenty Years (pp. 243254): GSDI Association Press.

Verduyn, P., Lee, D. S., Park, J., Shablack, H., Orvell, A., Bayer, J., . . Ethan, K. (2015).

Passive Facebook usage undermines affective well-being: Experimental and longitudinal evidence. Journal of Experimental Psychology, 144(2), 480-488. 
Weaver, K., Campbell, R., Mermelstein, R., \& Wakschlag, L. (2008). Pregnancy smoking in context: the influence of multiple levels of stress. Nicotine \& Tobacco Research, 10(6), 1065-1073. 


\section{FIGURES}

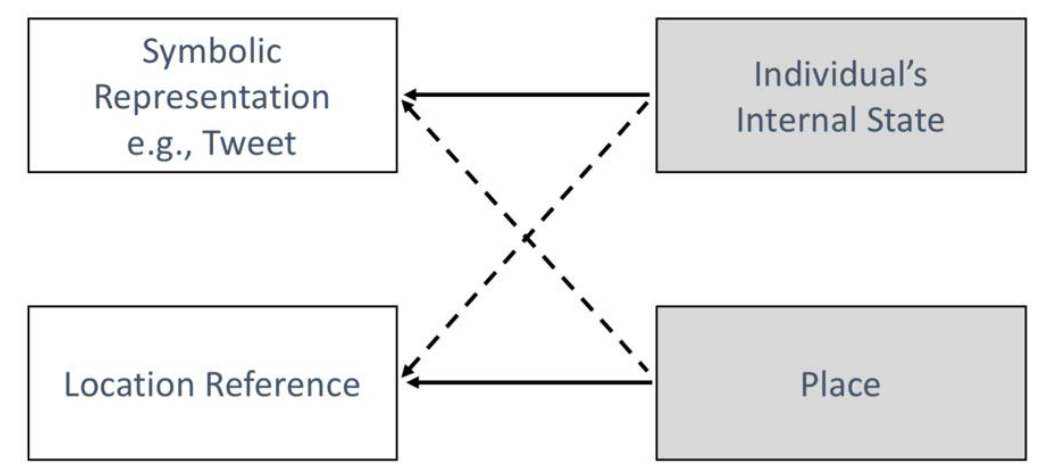

Figure 1 Schematic of relations between observed data (white boxes) and latent variables (shaded boxes) components of geosocial media analysis of health.

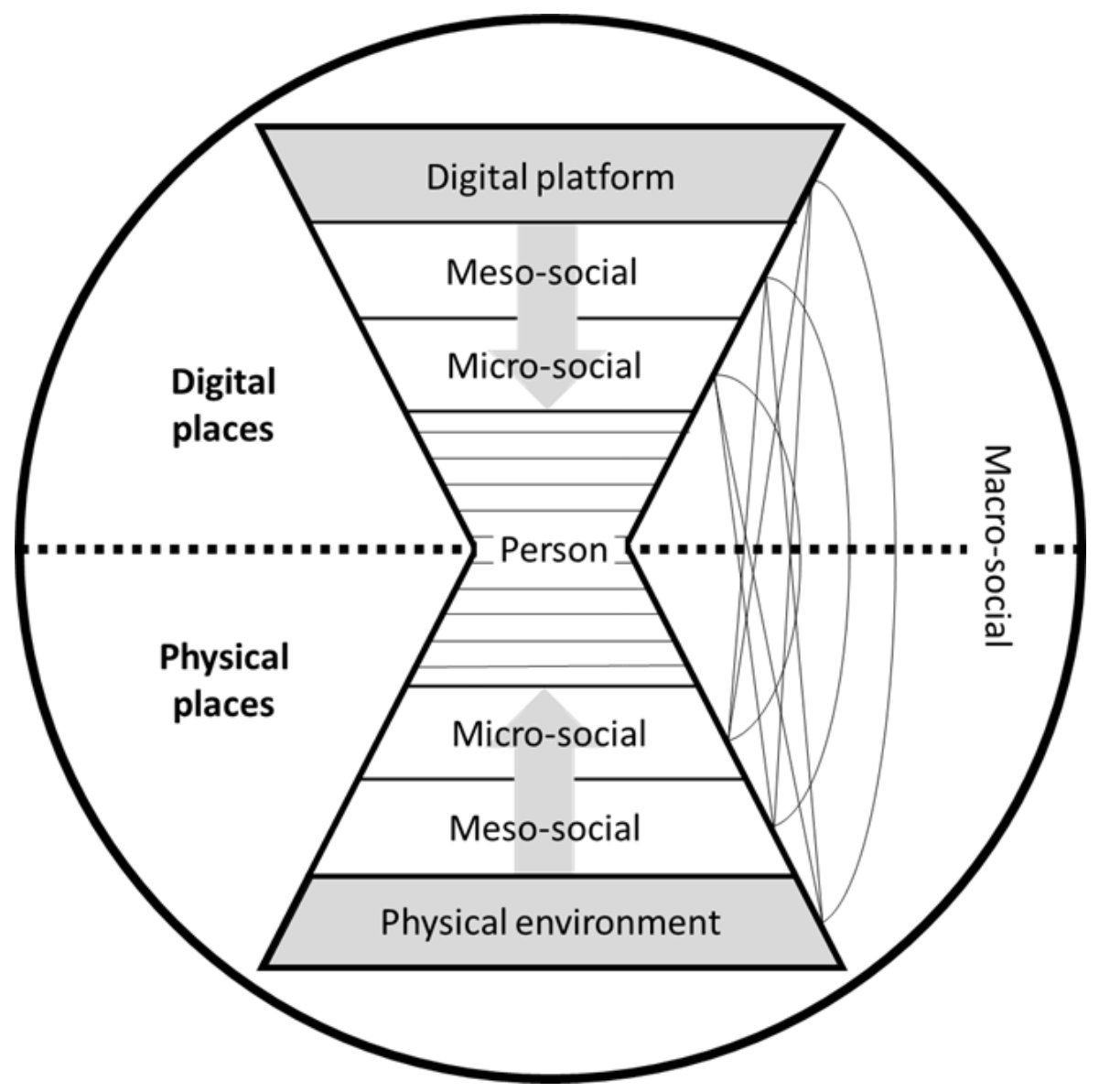

Figure 2. A Unified Ecological Framework for Place Effects on Well-being 


\section{A Unified Ecological Framework for Studying Effects of Digital Places on Well-being}

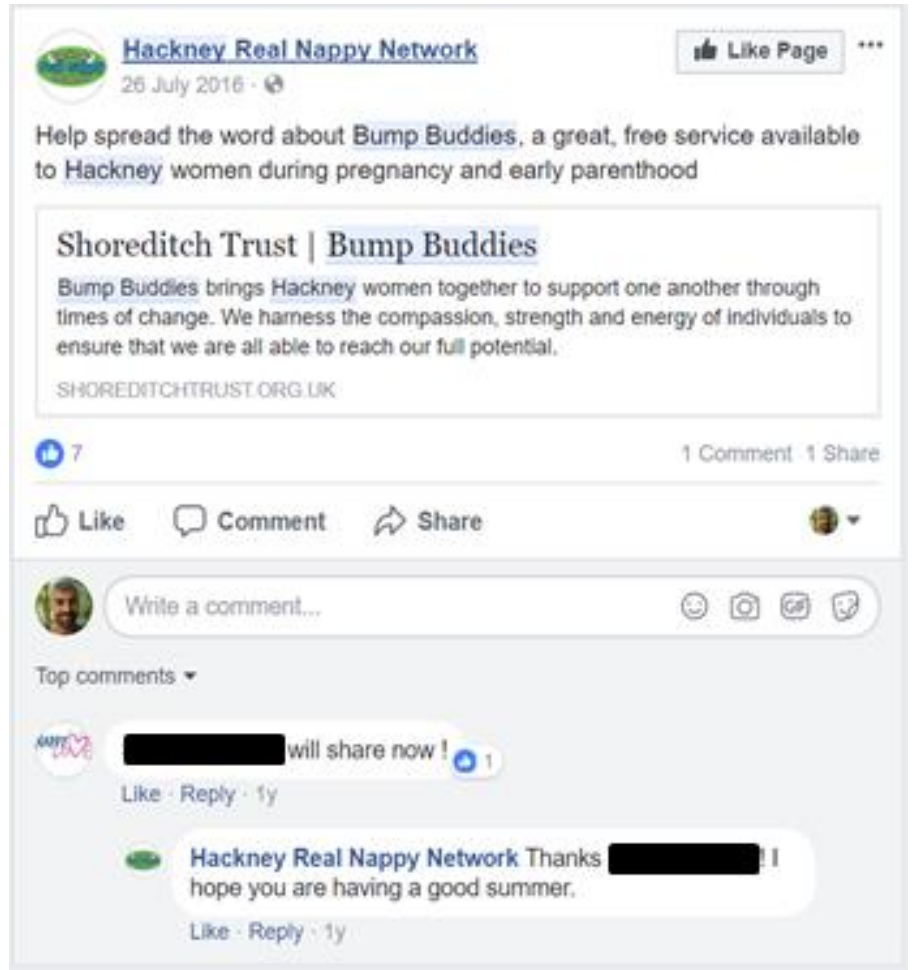

Figure 3. A public Facebook post from community-based organization (Hackney Real Nappy Network) about the Bump Buddies program. 


\section{Ethics statements}

This paper was describes a conceptual framework that is not based on the collection or analysis of any data from human subjects or otherwise; therefore, no research ethics statement is included in the manuscript. 